\title{
Evidence of a male sex pheromone in the round goby (Neogobius melanostomus)
}

\author{
Lynda D. Corkum $^{1, *}$, Wes J. Arbuckle ${ }^{1}$, Andrea J. Belanger ${ }^{1}$, Donald B. Gammon ${ }^{1}$, \\ Weiming $\mathrm{Li}^{2}$, Alexander P. Scott ${ }^{3} \&$ Barbara Zielinski ${ }^{1}$ \\ ${ }^{1}$ Department of Biological Sciences, University of Windsor, Ontario, Canada N9B 3P4; ${ }^{2}$ Department of \\ Fisheries and Wildlife, Michigan State University, East Lansing, MI 48824, USA; ${ }^{3}$ The Center for \\ Environment, Fisheries and Aquaculture Sciences, Weymouth Laboratory, Dorset DT4 8UB, UK; * Author \\ for correspondence (e-mail: corkum@uwindsor.ca; fax: +1-519-971-3609)
}

Received 12 December 2003; accepted in revised form 8 March 2004

Key words: behaviour, electro-olfactogram, Neogobius melanostomus, pheromone

\begin{abstract}
The reproductive success of the round goby (Neogobius melanostomus), an invasive fish, may be mediated by the use of pheromones. We hypothesized that reproductive male (RM) round gobies release a sex pheromone to which reproductive females (RF) respond. In this study, we compared behavioural and electrophysiological responses of reproductive and non-reproductive female round gobies to conspecific males. Results of behavioural experiments in the laboratory showed that RF spent significantly more time near the source of the male odour compared with odours from control water. However, RF did not distinguish between odours from non-reproductive male (non-RM) water and control water. Non-reproductive females (non-RF) were not attracted to odours released from RM or non-RM water. Results of electro-olfactogram (EOG) responses showed that both RF and non-RF discriminated between HPLC fractionated RM and non-RM odours. However, the EOG responses of RF were about eight-fold higher than non-RF exposed to RM odours. These findings confirm that RM round gobies release a pheromone signal that attracts RF. The results of this research may be useful in developing a control strategy using natural pheromones to disrupt the reproductive behaviour of the invasive round goby and to curtail its effects on native species.
\end{abstract}

\section{Introduction}

There are many invasive fishes within the Laurentian Great Lakes that have substantial adverse effects on communities (Hall and Mills 2000). For example, the invasion of the sea lamprey, Petromyzon marinus, a lethal parasite, led to the collapse of the commercial fishery of lake trout, Salvelinus namaycush, and lake whitefish, Coregonus clupeaformis (Smith and Tibbles 1980). Efforts in Great Lakes jurisdictions are being made (and more are needed) to control the entry of invasive species introduced through ballast water, canals, and recreational boating (Vásárhelyi and Thomas 2003). However, there are relatively few practices in place to control established invasive species without affecting non-target species or resulting in environmental damage.

Native to the Black and Caspian seas, the round goby was likely introduced to the Great Lakes by ballast water (Jude et al. 1992). The fish was first reported in 1990, quickly spread to all five Great Lakes, and has begun to invade the Mississippi River basin (Charlebois et al. 2001). Reasons for the proliferation of the round goby include its broad diet and availability of 
molluscan prey (adults eat mainly dreissenids), aggressiveness, high fecundity, multiple spawning habits (up to six times per year), and male parental care (Corkum et al. 2004). This reproductive strategy may be responsible, in part, for the tremendous increase in density and widespread distribution of the round goby in the Great Lakes (Lee 2003). The round goby has been shown to compete with native fish such as mottled sculpins, Cottus bairdi (Dubs and Corkum 1996; Janssen and Jude 2001), to feed on eggs and fry of native fishes (Nichols et al. 2003; Steinhart et al. 2004), and to alter ecological function by changing energy and contaminant pathways (Morrison et al. 2000). Thus, there is great value in reducing the reproductive success of this invasive predator.

Pheromone-based communication is critical to the maintenance of many fish populations through its effect on mating behaviour (Stacey and Sorensen 2002). Just as males use ornaments or elaborate displays to enhance their mating success, odours represent a strong signal to females and other males in sexual selection (Wyatt 2003). Long ago, commercial fishers deployed caged reproductive male lampreys and relied on the odour of males to attract females; the technique resulted in abundant catches (Fontaine 1938).

Round gobies are benthic fish that dwell in murky water among rocky habitats (Ray and Corkum 2001). The parental male round goby maintains and guards a nest with a single opening into which many females deposit eggs (Wickett and Corkum 1998; MacInnis and Corkum 2000). Although visual cues (guarding males are black rather than mottled) may not be effective in attracting females in dim light, water can readily transport body metabolites. The nest with a single opening facilitates both nest defense and the exchange of chemical signals. Chemical communication using sex pheromones may be crucial in regulating reproductive habits of round gobies. Sex pheromones have been defined by Karlson and Luscher (1959) as "substances that are excreted to the outside by an individual and received by a second individual of the same species in which they release a specific reaction, for example a definite behavior or developmental process".
Sex pheromones play a role in the spawning behaviour of gobiids. For example, Tavolga (1956) showed that odours from reproductive females enhanced sexual activity in reproductive males of the frillfin goby, Bathygobius soporator. Exposure of female black gobies, Gobius jozo $(=G$. niger $)$, to etiocholanolone-glucuronide (ETIO-g), a metabolite produced by the mesorchial glandular mass of the testis, stimulated attraction and egg deposition by ovulated females with post-ovulated females displaying significantly less attraction (Colombo et al. 1980). Recently, Murphy et al. (2001) showed that round gobies responded to synthetic pheromonal compounds (18-, 19-, and 21- carbon steroids) by increased gill ventilation and olfactory epithelial activity (measured using electro-olfactogram (EOG) responses).

Our hypothesis was that reproductive male (RM) round gobies release sex pheromone(s) to attract reproductive females (RF) to nests. To test this, we compared the behavioural and electrophysiological responses of reproductive and non-reproductive female (non-RF) round gobies to odours of conspecific reproductive and nonreproductive males (non-RM) in conditioned water (male washings). We first collected and concentrated water into which potential pheromones from male round gobies were released. Next, we conducted laboratory experiments to determine if both RF and non-RF spent more time near an odour source released by RM compared with non-RM round gobies. We also examined olfactory responses of females to male odours using EOG recordings. Understanding how female round gobies are attracted to a nesting RM is the first step in developing a pheromone-based strategy that could be used to disrupt the reproductive habits of the round goby to curtail its effect on native fishes.

\section{Materials and methods}

\section{Experimental animals}

Round gobies were collected in 2002 (MaySeptember) and 2003 (May-July) by angling in Canadian waters of the upper Detroit River and by trawling (Ontario Ministry of Natural 
Resources) in western Lake Erie. Fish were maintained in holding tanks (designated for separate sexes and for fish with different reproductive status) in the laboratory with a constant photoperiod $(16 \mathrm{~L}: 8 \mathrm{D})$ and with aerated, $18{ }^{\circ} \mathrm{C}$ flow-through dechlorinated water, gravel, and PVC tubing for shelters. Round gobies were fed Nutrafin ${ }^{\circledR}$ fish flakes.

Fish were sexed by the shape of the urogenital papilla, which is pointed in males and broad in females (Miller 1984). Reproductive status was determined by secondary sexual characters (ripe females had swollen abdomens) and by gonadal development (gonadosomatic index, GSI). The GSI was determined on each fish after it was used in an experiment. The mean (standard error, SE) GSI of RF and non-RF was $11.8(0.42)$ and 2.9 (0.28), respectively. Reproductive status was confirmed by examining oocyte development. Ovaries of RF contained eggs with diameters $2.16(0.14) \mathrm{mm}$, which were similar to round goby oocyte size within 1 week of spawning (Kulikova 1985). Female round gobies are iteroparous. The non-RF used in the experiments had not spawned in the laboratory before being tested, although it is possible that they had spawned previously in the field. Reproductive males (RM) exhibited typical black nuptial coloration and swollen cheeks (MacInnis and Corkum 2000). The mean (SE) GSI of RM and non-RM was $2.3(0.59)$ and $0.17(0.02)$, respectively. Seminiferous tubules and spermatic ducts were filled with spermatozoa in RM. Motile spermatozoa were collected from these males to confirm their reproductive status.

\section{Collection, extraction and HPLC fractionation of conditioned water}

Randomly selected male round gobies (RM and non-RM) were held individually in sterilized jars with 11 of dechlorinated tap water and an air stone. Each fish was kept in the jar for $4 \mathrm{~h}$ to allow sufficient time for the release of odours. The fish was removed from the jar and the "conditioned' water was then used in the behavioural experiments. For EOG trials, the conditioned water was filtered (Whatman size 4, Whatman Inc., Ann Arbor, MI) to remove debris and the filtrate (stored at $-20^{\circ} \mathrm{C}$ ) was always used within
3 months from the time of collection. The EOG recordings were obtained from females exposed to HPLC fractionated extracts of male conditioned water.

To prepare samples for EOG recordings, compounds were obtained from male conditioned water using C-18 solid phase extraction (SPE) cartridges (Waters, Milford, MA), followed by elution with methanol $(5 \mathrm{ml})$. The methanol extracts from $10 \mathrm{RM}(50 \mathrm{ml}$ total) or 10 nonRM were combined and dried in a rotary evaporator. The product was reconstituted in $100 \mu \mathrm{l}$ acetonitrile/water/trifluroacetic acid (28/72/0.01; $\mathrm{v} / \mathrm{v} / \mathrm{v})$ and then loaded onto an analytical reversephase HPLC column (Rainin Dynamax Microsorb; $5 \mu \mathrm{m}$ octadecylsilane; $4.6 \mathrm{~mm} \times 25 \mathrm{~cm}$; fitted with a $1.5 \mathrm{~cm}$ guard module). Two pumps delivered solvents through the column at a rate of $0.5 \mathrm{ml} \mathrm{min}^{-1}$. Solvent A was $0.01 \%$ trifluoroacetic acid (TFA) in distilled water; solvent B was $70 \%$ acetonitrile and $0.01 \%$ TFA in distilled water. The column was developed with a gradient of solvent $\mathrm{B}$ from 28 to $100 \%$ over $50 \mathrm{~min}$, at a flow rate of $4 \mathrm{ml} \mathrm{min}^{-1}$, and monitored with a PDA detector (Waters, Model 996). One-minute fractions were collected between 20 and $70 \mathrm{~min}$, the range where steroids typically elute (Murphy et al. (2001) showed that Neogobius melanostomus detected steroids, but not prostaglandins); $500 \mu \mathrm{l}$ of eluent constituted one HPLC fraction. All HPLC samples were diluted 1: $100(100 \mu \mathrm{l}$ of HPLC sample $+9900 \mu$ of dechlorinated tap water).

\section{Behavioural assay}

A laboratory experiment was conducted to determine if RF and non-RF responded to odours of water conditioned by RM and non-RM. In these tests, a female round goby was added to a tank $(0.90 \mathrm{~m}$ long $\times 0.28 \mathrm{~m}$ wide $\times 0.28 \mathrm{~m}$ high $)$ with 201 of $18{ }^{\circ} \mathrm{C}$ aerated, dechlorinated water. A shelter was provided at one end of the tank for the female and control aerated dechlorinated water or conditioned water (from RM or nonRM) was added at the opposite end of the tank. A sample of $500 \mathrm{ml}$ of either control or conditioned water was placed in an intravenous bag, secured above the tank. A valve on a Tygon ${ }^{\circledR}$ delivery tube regulated flow $\left(6 \mathrm{ml} \mathrm{min}{ }^{-1}\right)$ from 
the bag to the tank; outflow was removed from the opposite end of the tank at the same rate. After a female (either RF or non-RF) round goby was acclimated to the tank for $0.5 \mathrm{~h}$, we added control water for 15 min followed by conditioned water for $15 \mathrm{~min}$. There were five replicates for RF and four replicates for non-RF for each treatment. Each female round goby was used only once. We videotaped the activity of the fish in the tank using a colour camera (Hitachi Denshi VKC-370). The videotapes were analysed using a 2-D image analysis system (Peak Motus ${ }^{\circledR}$ Version 7.2) to determine the time that a female round goby spent in the far half of the tank near the input source of water. Unpaired $t$-tests were used to compare the mean time that females spent near the input source between control and conditioned water.

\section{Electro-olfactogram (EOG) assay}

The EOG recordings measure generator potentials of olfactory sensory neurons (Ottoson 1971). The EOG assays followed procedures outlined by Murphy et al. (2001). Assays were performed to measure the olfactory epithelial responses of $10 \mathrm{RF}$ and 10 non-RF to individual HPLC fractions, derived from both RM and non-RM conditioned water. Each of the 50 HPLC fractions was presented to females randomly and each fraction tested on a given female was sampled twice.

Randomly selected RF or non-RF were anaesthetized using low dosage $(0.05 \%)$ of 2-phenoxyethanol (Sigma, Oakville, ON). A female was placed in a perfusion chamber and a tube, placed in its mouth, continuously delivered oxygenated dechlorinated water. Differential EOG responses were recorded using two $\mathrm{Ag} / \mathrm{AgCl}$ electrodes (type IB 100-F-3; WPI Sarasota, FL) filled with $3 \mathrm{M} \mathrm{KCl}$ and bridged to saline gelatin $(8 \%)$ filled glass capillaries (tip diameter, $100 \mu \mathrm{m}$ ). The reference electrode was placed on the skin near the naris. The recording electrode was placed in the anterior nostril and adjusted to maximize responses to the standard odorant $10^{-5}$ L-alanine (Sigma, Oakville, ON). Previous immunocytochemical and ultrastructure analysis have shown abundant ciliated and microvillar olfactory sensory neurons in this region (Belanger et al. 2003).
Dechlorinated water was continuously perfused through the nostril and test odours were likewise applied to the posterior nostril. The stimulus duration for odorant application was $3 \mathrm{~s}$. Responses were recorded using a Grass preamplifier (7P122P), polygraph (Model 79) and a computer-assisted data acquisition and analysis system (Polyview, Version 2.5, Grass-Telfactor, West Warwick, RI). During the course of recording, the sensitivity to the amino acid standard, L-alanine $\left(10^{-5} \mathrm{M}\right.$, Murphy et al. 2001) was monitored every 10 tests to assess the quality and consistency of the recording. EOG recordings during exposure to a $3 \mathrm{~s}$ pulse of dechlorinated tap water (background water) that normally irrigated the nostril were made to ensure that there was no mechano-stimulation during odorant delivery, allowing $2 \mathrm{~min}$ between exposures to test solutions minimized olfactory adaptation.

Each of the 50 HPLC fractions was randomly selected for application during each EOG run. Blank HPLC fractions were tested to ensure that the solvent used during the extraction and HPLC procedures did not account for the olfactory responses observed. The blank was prepared by passing untreated dechlorinated water through the SPE cartridge followed by methanol elution and HPLC fractionation. Fractions from this blank preparation did not stimulate EOG responses from RF or non-RF.

The amplitude of each EOG response was measured from baseline to peak and expressed in millivolts. Hotelling's $t$-test (each HPLC fraction represented a dependent variable) was used to determine if there was an overall significant difference in mean EOG response of females (RF and non-RF) to RM and non-RM odours.

\section{Results}

Movement by female round gobies during the acclimation period (no inflow) of the behavioural assay was in various directions, typically around the shelter. In contrast, females moved toward the source of inflow during both control and treatment periods. Our expectations were that female (especially RF) round gobies would spend more time near the source of male odours compared with the source of control water. As 
expected, RF spent significantly more time (mean $\pm \mathrm{SE}$ ) in the far half (i.e., the far half of the tank near the odour source) of the tank when odours from RM $(700 \pm 56$ s) were delivered compared with odours from control water $(237 \pm 133 \mathrm{~s})(1$-tailed $t$-test $(\mathrm{df}=8)=3.214, \quad P<$ in the far half of the tank between odours from non-RM (342 $\pm 201 \mathrm{~s})$ and control water $(390 \pm 230$ s) trials. Non-reproductive females were unable to distinguish between odours from RM or non-RM when each was compared with control water (Figure 1).
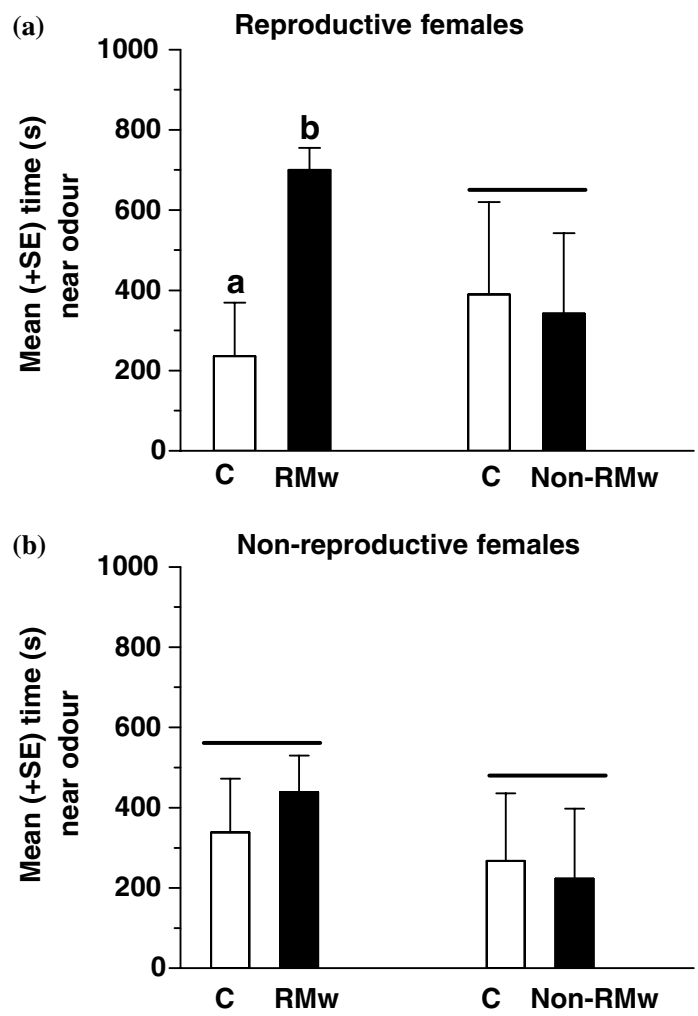

Figure 1. Mean (+ standard error, SE) time (s) spent by (a) $\mathrm{RF}$ and (b) non-RF in response to control water (open bars) and water conditioned by males (solid bars). There are two types of male conditioned water: $\mathrm{RMw}$, reproductive male water; non-RMw, non-reproductive male water. Differences in lower case letters, $a$ and $b$, indicate significant differences ( $t$-test) between the time spent in the far half of the tank near the input source when RF were exposed to control water or RMw $(t=3.214, P<0.01)$. A solid line indicates that there are no significant differences in time spent near the input source when control and male conditioned water trials were compared.
The response of $\mathrm{RF}$ to fractionated male odours was about eight-fold higher than the response of non-RF to male odours (Figure 2). All of the HPLC fractions of the RM conditioned water extract elicited an EOG response from RF (Figure 2a). Reproductive females exhibited significantly different results in EOG levels to RM fractions than to non-RM HPLC fractions (Hotelling's $t$-test; $T^{2}=39.566, P<0.0001$ ). The largest differences in mean EOG activity of RF to RM and non-RM occurred between HPLC fractions 30 and $40 \mathrm{~min}$ where $\mathrm{RF}$ responded to several fractions (Figure 2a). Interestingly, EOG responses of non-RF also differed between RM and non-RM fractionated odours (Figure 2b). There was an overall significant difference in EOG responses by non-RF to RM fractions compared with non-RM HPLC fractions (Hotelling's $t$-test; $\left.T^{2}=21.511, P<0.0001\right)$.
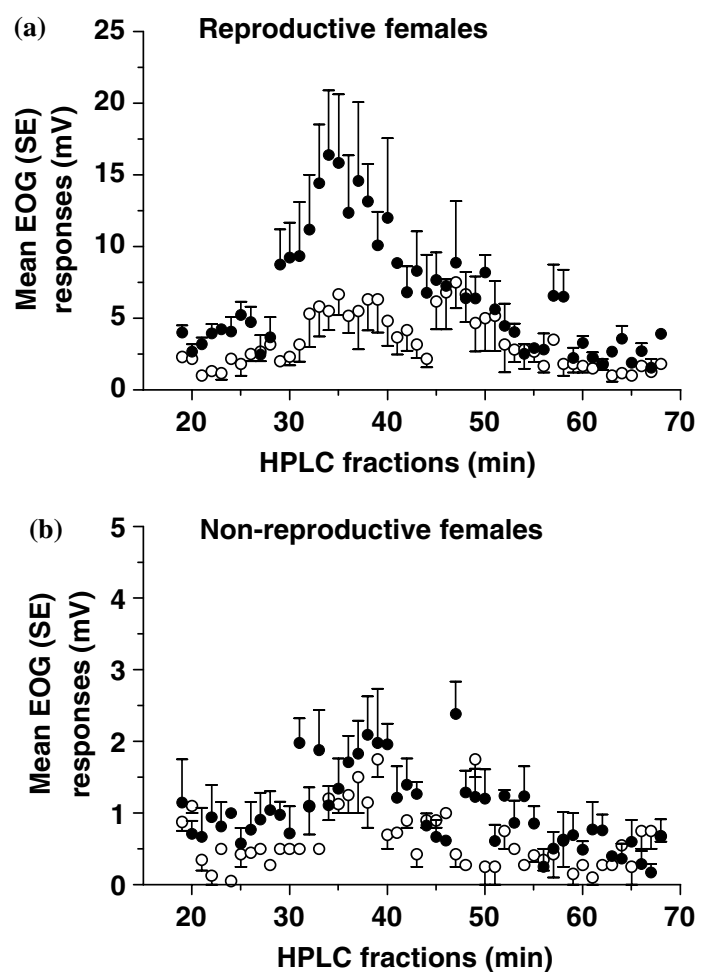

Figure 2. Mean (SE) electro-olfactogram (EOG) responses of (a) RF and (b) non-RF to HPLC fractions of methanol eluate following C-18 solid phase extraction of reproductive male water (solid circles) and non-reproductive male water (open circles). 


\section{Discussion}

Our results support the possibility that odours of mature male round gobies induce behavioural and EOG responses in mates that are typical of reproductive function. In fish species that have been studied (including the round goby, Belanger et al. 2003), it has been shown that most species rely on the olfactory sense to mediate reproduction (Stacey and Sorensen 2002). In our study, washings from RM round gobies induced conspecific RF to move to the input source of male water and to spend more time near the source of male odour compared with control water. The $\mathrm{RF}$ did not differ in their response to odours from non-RM water compared with control water. Moreover, non-RF were not attracted to odours released from RM or non-RM washings. These findings confirm that RM round gobies release a chemical cue that guides a RF to a specific source, i.e., a nest occupied by a parental male. Field studies have shown that several female round gobies (in some cases up to 15 females) enter a nest to deposit eggs (MacInnis and Corkum 2000). In many cases, nests of the round goby are in deep water with low visibility (Wickett and Corkum 1998). Hence, water-soluble pheromones may be the most useful signal that males use to attract spawning females. The odours to which RF respond give them a better chance of finding a male's nest.

Earlier, Colombo et al. (1977, 1979, 1980) showed that in the black goby, Leydig-like cells in the mesorchial gland of the testis, synthesized ETIO-g (a 19-carbon steroid), which was a signal for sexual recognition. Only post-ovulatory (ready to spawn) female black gobies moved towards ETIO-g that was pumped into the tank (Colombo et al. 1980); there was no response to the odour by females that had already deposited eggs (Colombo et al. 1980). Although it has not been determined that round gobies release ETIO-g, Murphy et al. (2001) showed that female round gobies increased their basal ventilation rate in response to three synthetic steroids (androsteronesulfate, etiocholanolone (ETIO), and ETIO-g). In Murphy's study, adult round gobies were tested, but the fish were not necessarily ready to spawn and no fish was observed to move toward any of the steroids. In another laboratory study, Belanger
(2002) showed that gill ventilation response by female round gobies to synthetic ETIO was significantly greater in summer than winter, suggesting that females respond more readily to odours during the spawning season. Again, no movement by females was detected when exposed to ETIO (Belanger 2002). Evidently, pheromones are released by sexually mature male round gobies and a female responds to the odour by moving to the male only when she is ready to spawn.

In contrast to the results of the behavioural experiments where only RF responded to RM odours, both RF and non-RF were able to discriminate between HPLC fractions isolated from both RM and non-RM water. Interestingly, even non-RF exhibited significantly higher EOG responses when exposed to HPLC fractions isolated from RM odour compared with non-RM odours. As expected, the EOG responses by RF were noticeably greater (up to eight-fold higher) than non-RF responses when exposed to HPLC fractionated, hydrophobic extracts of RM water. Indeed, EOG responses by RF to several HPLC fractions between 30 and $40 \mathrm{~min}$ suggest that females likely respond to a mixture of steroids. This finding is supported by Murphy et al. (2001), who showed that 19 of 144 synthetic steroids induced an EOG response in round gobies. Of these compounds, conjugated steroids (e.g., ETIO-g), which are more soluble in water than unconjugated steroids (e.g., ETIO), are more likely to be used in pheromone signaling (Scott and Vermeirssen 1994; Vermeirssen and Scott 1996).

Results from our behavioural and electrophysiological responses by RF to male odours support the hypothesis that mature females actively respond by moving to sex attractants released by the male. The application of this research may lead researchers to explore the possible development of a control strategy using natural pheromones to disrupt reproductive behaviours of the invasive round goby. Because juvenile and adult round gobies can feed on eggs of native fishes (lake sturgeon, Nichols et al. 2003; smallmouth bass, Steinhart et al. 2004) and displace native benthic fishes (Janssen and Jude 2001), there is great value in reducing the reproductive success of this invasive predator.

Recently, Li et al. (2002) showed that RF sea lamprey that are ready to spawn are attracted to 
pheromone odours released by spermiating males. Use of pheromones may lead to effective control measures of invasive species at specific locations. Our study, similar in approach to Li et al (2002), has potential for the control of the invasive round goby, Neogobius melanostomus.

\section{Acknowledgements}

We are grateful for the assistance of the Ontario Ministry of Natural Resources (Pt. Dover and Wheatley stations) for their assistance with fish collections. We thank Dr J. Green (Dept. of Chemistry and Biochemistry, University of Windsor) for his advice on organic chemistry and the use of his laboratory facilities and Dr L. Buchanan (Department of Psychology, University of Windsor) for the use of her image analysis system. Dr. S-S. Yun (Department of Fisheries and Wildlife, Michigan State University) kindly provided assistance with the HPLC analysis. We thank two anonymous reviewers for comments that improved this manuscript. This study was supported by the Michigan Great Lakes Protection Fund and NSERC.

\section{References}

Belanger RM (2002) Morphology and histochemistry of the peripheral olfactory organ and behavioural responses by the round goby, Neogobius melanostomus, to putative pheromones and conspecific extracts. MSc Thesis, Department of Biological Sciences, University of Windsor, $137 \mathrm{pp}$

Belanger RM, Smith CM, Corkum LD and Zielinski B (2003) Morphology and histochemistry of the peripheral olfactory organ in the round goby, Neogobius melanostomus (Teleostei: Gobiidae). Journal of Morphology 257: 62-71

Charlebois PM, Corkum LD, Jude DJ and Knight C (2001) The round goby (Neogobius melanostomus) invasion: current research and future needs. Journal of Great Lakes Research 27: 263-266

Colombo L, Belvedere PC and Pilati A (1977) Biosynthesis of free and conjugated $5 \beta$-reduced androgens by the testis of the black goby, Gobius jozo L. Bollettino di Zoologia 44: 131-144

Colombo L, Belvedere PC and Marconato A (1979) Biochemical and functional aspects of gonadal biosynthesis of steroid hormones in teleost fish. Proceedings of the Indian National Academy of Sciences B 45: 226-234

Colombo L, Marconato A, Belvedere PC and Frisco C (1980) Endocrinology of teleost reproduction: a testicular steroid pheromone in the black goby, Gobius jozo L. Bollettino di Zoologia 47: 355-364
Corkum LD, Sapota MR and Skora KE (2004) The round goby, Neogobius melanostomus, a fish invader on both sides of the Atlantic Ocean. Biological Invasions 6: 173-181

Dubs DOL and Corkum LD (1996) Behavioral interactions between round gobies (Neogobius melanostomus) and mottled sculpins (Cottus bairdi). Journal of Great Lakes Research 22: 838-844

Fontaine M (1938) La lamproie marine. Sa peche et son importance economique. Bulletin de la Societe d'Oceanographie de France 17: 1681-1687

Hall SR and Mills EL (2000) Exotic species in large lakes of the world. Aquatic Ecosystem Health and Management 3: 105-135

Janssen J and Jude DJ (2001) Recruitment failure of mottled sculpin Cottus bairdi in Calumet Harbor, Lake Michigan, induced by the newly introduced round goby Neogobius melanostomus. Journal of Great Lakes Research 27: 319-328

Jude DJ, Reider RH and Smith GR (1992) Establishment of Gobiidae in the Great Lakes basin. Canadian Journal of Fisheries and Aquatic Sciences 49: 416-421

Karlson P and Luscher M (1959) "Pheromones": a new term for a class of biologically active substances. Nature 183: 55-56

Kulikova NI (1985) The effect of chorionic gonadotropin in growth and maturation of the oocytes of the round goby, Neogobius melanostomus. Journal of Ichthyology 25: 86-98

Lee VA (2003) Factors regulating biomass and contaminant uptake by round gobies (Neogobius melanostomus) in western Lake Erie. MSc Thesis, Department of Biological Sciences, University of Windsor, $118 \mathrm{pp}$

Li W, Scott AP, Siefkes MJ, Yan HG, Liu Q, Yun SS and Gage DA (2002) Bile acids secreted by male sea lamprey that act as a sex pheromone. Science 296: 138-141

MacInnis AJ and Corkum LD (2000) Fecundity and reproductive season of the round goby Neogobius melanostomus in the upper Detroit River. Transactions of the American Fisheries Society 129: 136-144

Miller PJ (1984) The tokology of gobioid fishes. In: Potts GW and Wooton RJ (eds) Fish Reproduction, Strategies and Tactics, pp 119-153. Academic Press, London

Morrison HA, Whittle DM and Haffner GD (2000) The relative importance of species invasions and sediment disturbance in regulating chemical dynamics in western Lake Erie. Ecological Modelling 125: 279-294

Murphy CA, Stacey NE and Corkum LD (2001) Putative steroidal pheromones in the round goby, Neogobius melanostomus: olfactory and behavioral responses. Journal of Chemical Ecology 27: 443-470

Nichols SJ, Kennedy G, Crawford E, Allen J, French III J, Black G, Blouin M, Hickey J, Chernyák S, Haas R and Thomas M (2003) Assessment of lake sturgeon (Acipenser fulvescens) spawning efforts in the lower St. Clair River, Michigan. Journal of Great Lakes Research 29: 383-391

Ottoson D (1971) The electro-olfactogram. In: Biedler LM (ed) Handbook of Sensory Biology, pp 95-131. SpringerVerlag, New York

Ray WL and Corkum LD (2001) Habitat and site affinity of the round goby. Journal of Great Lakes Research 27: 329-334 
Scott AP and Vermeirssen EL (1994) Production of conjugated steroids by teleost gonads and their role as pheromones. In: Davey KG, Peter RE and Tobe SS (eds) Perspectives in Comparative Endocrinology, pp 645-654. National Research Council of Canada, Ottawa

Smith BR and Tibbles JJ (1980) Sea lamprey (Petromyzon marinus) in Lake Huron, Michigan, and Superior: history of invasion and control, 1936-1978. Canadian Journal of Fisheries and Aquatic Sciences 37: 1780-1801

Stacey N and Sorensen P (2002) Hormonal pheromones in fish. In: Pfaff D, Arnold A, Etgen AM, Fahrbach SE and Rubin RT (eds) Hormones, Brain and Behavior, Vol. 2, Non-mammalian Hormone-Behavior Systems, pp 375-434. Elsevier, New York

Steinhart GB, Marschall EA and Stein RA (2004) Round goby predation on smallmouth bass offspring in nests during simulated catch-and-release angling. Transactions of the American Fisheries Society 133: 121-131
Tavolga WM (1956) Visual, chemical and sound stimuli as cues in the sex discriminatory behaviour of the gobiid fish Bathygobius soporator. Zoologica-NY 41: 49-65

Vásárhelyi C and Thomas VG (2003) Analysis of Canadian and American legislation for controlling exotic species in the Great Lakes. Aquatic Conservation Marine and Freshwater Ecosystems 13: 417-427

Vermeirssen EL and Scott AP (1996) Male priming pheromone is present in bile, as well as in urine, of female rainbow trout. Journal of Fish Biology 58: 1039-1045

Wickett RG and Corkum LD (1998) Nest defense by the nonindigenous fish, the round goby, Neogobius melanostomus (Gobiidae), on a shipwreck in western Lake Erie. Canadian Field-Naturalist 112: 653-656

Wyatt TD (2003) Pheromones and Animal Behaviour Communication by Smell and Taste. Cambridge University Press, Cambridge, 391 pp 